\title{
Crowd sourcing to bridge the gap between science and public health
}

\begin{abstract}
A One Health approach has been promoted for twenty years to strengthen control and prevention of zoonotic diseases. But barriers remain particularly limiting effective intersectoral cooperation between science and public health. Crowdsourcing is an online, distributed, problem-solving, and production model, which generally includes four elements: 1) An institution or an individual has a task or question, 2) a community (crowd) solves the task on a voluntary basis, 3) an online-platform facilitates the interaction of both sides, and 4) the result is an added value for the questioner as well as the crowd. We propose a crowdsourcing approach where individual scientists and public and veterinary health representatives can act both as questioners or crowd members. The combination of an online exchange forum, an integrated search database and targeted training making use of innovative media has the potential to break down historical barriers limiting intersectoral cooperation. This approach can encourage information exchange, improve translation of research into policy and practice and lead to more targeted science and advanced training.
\end{abstract}

Keywords: engagement, exchange forum, network, One Health, participation, training, translation
Volume 7 Issue 4 - 2018

\author{
Birgit Schauer \\ Institute for Community Medicine, University Medicine \\ Greifswald, Germany \\ Correspondence: Birgit Schauer, Institute for Community \\ Medicine, University Medicine Greifswald, Germany, \\ Tel +493834866685, Email Birgit.Schauer@uni-greifswald.de
}

Received: July 17, 2017| Published: July 19, 2018
Abbreviations: CS, crowdsourcing; OH, One Health; PHS, public health sector; VHS, veterinary health sector

\section{Introduction}

Zoonotic infections including antimicrobial resistance were responsible for $65 \%$ of 215 identified human diseases ${ }^{1}$ and $60 \%$ of 335 emerging infectious diseases. ${ }^{2}$ Effective cooperation between stakeholders from different sectors and disciplines is required to optimize prevention and control of zoonotic diseases and antimicrobial resistance. A One Health $(\mathrm{OH})$ approach has been promoted since at least $1999,{ }^{3}$ which can be defined as "the collaborative effort of multiple disciplines - working locally, nationally, and globally - to attain optimal health for people, animals and the environment'. ${ }^{4}$ But the effectiveness of implementation is often limited. ${ }^{3}$ Whilst $\mathrm{OH}$ funding opportunities generate attractions for medical and veterinary scientists to cooperate, they are less effective in strengthening intersectoral cooperation between scientists and representatives of the public and veterinary health sectors (PHS and VHS; jointly termed "public health professionals") at the national, regional and local levels. An Australian study ${ }^{5}$ identified (a) cultural differences between scientists and decision-makers, (b) institutional barriers within decisionmaking agencies, and (c) the inaccessibility of science to decision-makers as factors preventing intersectoral knowledge exchange. These imminent challenges can only be addressed by promoting opportunities for scientists and public health representatives to interact. Hence, researchers and public health professionals need to strive for more effective engagement even if this challenges the current ways in which science and public health professionals work. ${ }^{6}$

Crowdsourcing (CS) is 'an online, distributed, problem-solving, and production model that uses the collective intelligence of networked communities for specific purposes ${ }^{7}$ and generally includes four elements: $\left.{ }^{8} 1\right)$ An institution or an individual has a task or question, 2) a community (crowd) solves the task on a voluntary basis, 3) an online-platform facilitates the interaction of both sides and 4) the result is an added value for the questioner as well as the crowd. Whilst CS has been successfully applied in other fields, its potential for improving public health ${ }^{7}$ and intersectoral cooperation between scientists and public health professionals in sense of $\mathrm{OH}$ is currently underexplored. This opinion paper proposes a CS initiative targeting science and public health, which has the potential to a) strengthen information exchange, b) inform research needs, c) strengthen translation of research into policy and practice, and d) enhance the effectiveness of training. On the one hand, translation of research into policy and practice will benefit from input from PHS and VHS representatives regarding research needs and dissemination as these are the ones working directly with zoonotic diseases throughout the country and on a daily basis. Public health in turn will profit from better translation of research and opportunities to communicate and discuss experiences and clarify questions. For zoonotic diseases, the target groups comprise medical and veterinary scientists and PHS and VHS representatives at the national, regional and local levels. Individual scientists and PHS and VHS representatives can act both as a questioner or crowd member as part of the proposed CS initiative. Interactions can take place within a target group (e.g. within PHS only) or between target groups. The following details only represent examples, which can be adjusted: The eligibility of participation is verified upon a participant's registration to allow internal discussions take place in a password-protected online area. Participants can set up email alerts and inform themselves via an intranet site about current offers (e.g. training, discussion groups), outstanding tasks (e.g. questions to be answered) and ongoing exchanges. Full access however requires a membership, which can be obtained via a voluntary contribution, e.g. of at least 20 minutes per month to stimulate active contributions, or a membership fee. Members can for example ask / comment on questions, indicate needs for advanced training or research, present scientific results or project proposals for discussion or form working groups to address a given topic or contribute to research (e.g. survey participation). Voluntary network promoters can recruit external experts in a targeted manner if information needs cannot be covered by forum members alone. A moderator maintains the forum and search database and every month presents a discussion topic, a literature overview and one pre-selected scientific article. Each month, members can vote, which topics should be targeted and thus influence the agenda. The search database is a valuable tool to inform current and future projects (e.g. planned research, advanced training). Finally, innovative media are used to address information or training needs in a targeted manner. 


\section{Discussion}

Especially given the global emergence of zoonotic diseases and antimicrobial resistance, it is imperative to address historical barriers and try new approaches to implement $\mathrm{OH}$ more effectively in practice. Currently, PHS and VHS representatives, especially at the local level, have no or little opportunity to share and discuss their experiences, ask questions or influence the training and research agenda. This CS initiative offers opportunities for engagement and empowers those who are most directly responsible for preventing and controlling zoonotic diseases. Unfortunately, a scientist's performance is solely measured based on publications and impact factors (social dilemma), which stands in stark contrast to the requirement of the $\mathrm{OH}$ agenda to foster engagement between scientists and public health professionals. Hence, the judgment of scientific performance may need to be re-assessed to promote intersectoral knowledge exchange possibly accounting for the frequency and quality of interactions, the practicality of produced research and effectiveness of translation. Empowering PHS and VHS representatives to directly interact within their own and with the other target groups is likely to widen the perspectives of all target groups and thus encourage systems thinking, which has been promoted to address the complexity of zoonotic diseases more effectively. ${ }^{9,10}$

\section{Conclusion}

This proposed CS initiative can offer many benefits ranging from enhanced information exchange and provision of a networking platform to improved translation of scientific findings into policy, practice, and targeted science and advanced training.

\section{Acknowledgement}

None.

\section{Conflict of interest}

None.

\section{References}

1. Smith KF, Goldberg M, Rosenthal S, et al. Global rise in human infectious disease outbreaks. JR Soc Interface. 2014;11(101):20140950.

2. Jones KE, Patel NG, Levy MA, et al. Global trends in emerging infectious diseases. Nature. 2008;451(7181):990-993.

3. Gibbs EPJ. The evolution of One Health: a decade of progress and challenges for the future. Vet Rec. 2014;174(4):85-91.

4. American Veterinary Medical Association. One Health: A New Professional Imperative, in One Health Initiative Task Force: Final Report; 2008.

5. C vitanovic CJ, Mc Donald, AJ Hobday. From science to action: Principles for undertaking environmental research that enables knowledge exchange and evidence-based decision-making. $J$ Environ Manage. 2016;183(3):864-874.

6. Kingsley P, EM Taylor. One Health: competing perspectives in an emerging field. Parasitology. 2017;144(1):7-14.

7. Brabham DC, Ribisl KM, Kirchner TR, et al. Crowdsourcing applications for public health. Am J Prev Med. 2014;46(2):179-187.

8. Ludwig Boltzmann Gesellschaft. Crowdsourcing Research Questions in Science; 2017.

9. Anonymous Tackling whicked problems: A public policy perspective, Australian Public Service Commission; 2013.

10. Leischow SJ, Best A, Trochim WM, et al. Systems Thinking to Improve the Public's Health. Am J Prev Med. 2008;35(2 Suppl):S196-S203. 